\title{
Perceptions of the learning environment in higher specialist training of doctors: implications for recruitment and retention
}

\author{
Vinette Cross, ${ }^{1}$ Carolyn Hicks, ${ }^{2}$ James Parle $^{2}$ \& Stephen Field ${ }^{3}$
}

INTRODUCTION Career choice, sense of professional identity and career behaviour are influenced, subject to change and capable of development through interaction with the learning environment. In this paper workplace learning discourses are used to frame ongoing concerns associated with higher specialist training. Data from the first stage of a multimethods investigation into recruitment into and retention in specialties in the West Midlands is used to consider some possible effects of the specialist learning environment on recruitment and retention.

METHODS The aim of the study was to identify issues, through interviews with 6 consultants and questionnaires completed by specialist registrars from specialties representing a range of recruitment levels. These would inform subsequent study of attributes and dispositions relevant to specialist practice and recruitment. The data were analysed using $\mathrm{NVivo}^{\odot}$ software for qualitative data management.

RESULTS Participants' perceptions are presented as bipolar dimensions, associated with: curriculum structure, learning relationships, assessment of learning, and learning climate. They demonstrate ongoing struggle between different models of workplace learning.

CONCLUSION Changes in the postgraduate education of doctors seem set to continue well into the future. How these are reflected in the balance between workplace learning models, and how they influence doctors' sense of identity as specialists

${ }_{1}^{1}$ School of Health, University of Wolverhampton, Wolverhampton, UK ${ }^{2}$ School of Health Sciences, University of Birmingham, Birmingham, UK ${ }^{3}$ West Midlands Deanery, Birmingham, UK

Correspondence: Dr Vinette Cross, School of Health, University of Wolverhampton, Molineaux Street, Wolverhampton WV1 1SB, UK. Fax: 00441902 518660; E-mail: vinette.cross@wlv.ac.uk suggests a useful basis for examination of career satisfaction and recruitment to specialties.

KEYWORDS education, medical, graduate; *specialism; *career choice; teaching/*methods; clinical competence/ standards; professional autonomy; attitude of health personnel; perception; curriculum; consultants; job satisfaction; personnel selection; medical staff, hospital; questionnaires; England.

Medical Education 2006; 40: 121-128

doi:10.1111/j.1365-2929.2005.02382.x

\section{INTRODUCTION}

Career choice, sense of professional identity and career behaviour are influenced strongly by their interaction with the learning environment in which they are placed. Hence consideration of this environment is central to exploring how these factors may change. ${ }^{1-3}$ In medicine, as elsewhere, career satisfaction can be adversely affected by ambiguity or lack of congruence between a personally envisaged role or identity and how the role can be enacted in reality. ${ }^{4,5}$ Clearly, it is important that doctors' career choices sustain their long-term interest and commitment, and that the right person with appropriate personal traits and clinical experience is recruited and sustained in the right job. Thus, the quality and possibilities afforded by particular learning environments have implications for recruitment and retention, as well as attributes and dispositions (habits of mind) looked for in potential applicants to specialties.

\section{The specialist learning environment}

Learning environments comprise a range of elements, such as atmosphere, learning opportunities, 


\section{Overview}

\section{What is already known on this subject}

Higher specialist learning environments are influenced by reconfiguration of health care and medical education. How workplace performance is acknowledged and judged is shaped by culture and values.

\section{What this study adds}

Models of workplace learning provide a framework for examining discrepancies between policy and practice in higher specialist training. Effective co-existence between different workplace learning models could enrich higher specialist learning environments and enhance professional identity.

\section{Suggestions for further research}

How do different workplace learning models inform selection and career satisfaction in higher specialist practice?

and attitudes to learning and teaching. Together, these generate a climate that may be more, or less, conducive to effective learning and career satisfaction. ${ }^{6,7}$ Extensive work on developing reliable measures of the quality of learning environments has focused on both the undergraduate and postgraduate medical experience. ${ }^{8-10}$ However, the pace of change demanded by central policy on medical education and health care delivery and the uncertainty this entails make it important that postgraduate deaneries keep the learning environment constantly under review. This is particularly important for specialties in which recruitment of new graduates is difficult. The Calman Report (1993) ${ }^{11}$ replaced timebased, experiential apprenticeships with competencebased structured programmes with fixed end-points. Specialist registrars are now assessed regularly against specialty-specific criteria. Simultaneously, there is increased emphasis on self-motivation, self-direction and collaboration between trainees and their educational supervisors. ${ }^{12-14}$ Reconfiguring the process that transforms junior doctors into career specialists has implications for the culture of the workplace, the nature of the learning and teaching experience for specialist doctors, the quality of learning outcomes and subsequent career behaviour.

\section{The aim of this study}

This paper explores perceptions of the learning and teaching experience among consultants and specialist registrars (trainees) working in the West Midlands. The aim was to undertake a small-scale exploratory study to provide insights that could inform both local programme development and serve as precursors to more extensive investigation into attributes and dispositions relevant to specialist practice and recruitment.

\section{METHODS}

Six specialties were selected to represent a range of local recruitment levels as indicated by the previous year's competition ratio (total number of applicants divided by positions offered) and proportion of suitable applicants. They comprised 'oversubscribed' specialties (high recruitment, high applicant suitability), 'neutral' specialties (high recruitment, variable applicant suitability) and 'undersubscribed' specialties (low recruitment). The specialties were gastroenterology, paediatrics (oversubscribed); anaesthetics, trauma and orthopaedics (neutral); adult psychiatry, histopathology (undersubscribed). Because the aim of the study was simply to get a feel for the issues, 2 non-probability sampling methods were employed. Purposive sampling of a senior consultant from each specialty took place on the basis of their extensive experience as an educational supervisor, assessor, evaluator and organiser of specialist training $(n=6)$. Convenience sampling of specialist registrars across all 6 specialties included a range of training years, female/male participants, UK/non-UK basic training, and flexible/full-time route perspectives $(n=40)$. Each consultant took part in a semi-structured interview lasting 1 hour. The registrars completed a questionnaire about their choice of specialty, which included an open response question about specialist training in the West Midlands. The interview guide and questionnaire were developed and piloted with the help of 2 consultants not involved in the study. This paper addresses the specific issues of:

1 how lead educators in the identified specialties feel about changes in specialist training;

2 what effects they perceive on the learning environment for specialist registrars in their specialty;

3 what effects they perceive in terms of specialist registrars' learning behaviour, and

4 how registrars in training feel about the West Midlands' specialist training programme. 


\section{Data analysis}

Qualitative data from the interviews and questionnaires were coded and compared using a combination of manual and computer-assisted methods $\left(\mathrm{NVivo}^{\odot}\right.$ software for qualitative data management). ${ }^{15}$ Interpretation and inferences from the findings were validated through ongoing discussion of emerging concepts and themes within the research team and by checking back with 3 of the interview participants.

\section{RESULTS}

Participants' responses are categorised under 4 headings: effects of curriculum structure, nature of learning relationships, approach to assessment of learning, and prevailing learning climate (Fig. 1). Under each of these headings responses are grouped at opposite poles of a continuum. For example, 'effects of curriculum structure' range from 'survival' to 'ownership'. Illustrative responses are identified by specialty and role $(\mathrm{SpR}=$ specialist registrar, $\mathrm{C}=$ consultant $)$.

\section{Effects of curriculum structure}

Participants generally endorsed a more structured curriculum. For example, registrars' comments included '....well-structured, all major clinical and non-clinical areas seem to be covered...' and '...monthly training days are very relevant'.

Discussion of the new curriculum structure revealed contrasting views of self-directed learning among the consultants. Insofar as self-directed learning epitomises learners grasping control of their own learning process, the relatively unstructured approach of the apprenticeship tradition was seen as promoting a 'survival' approach that aimed to allow the navigation

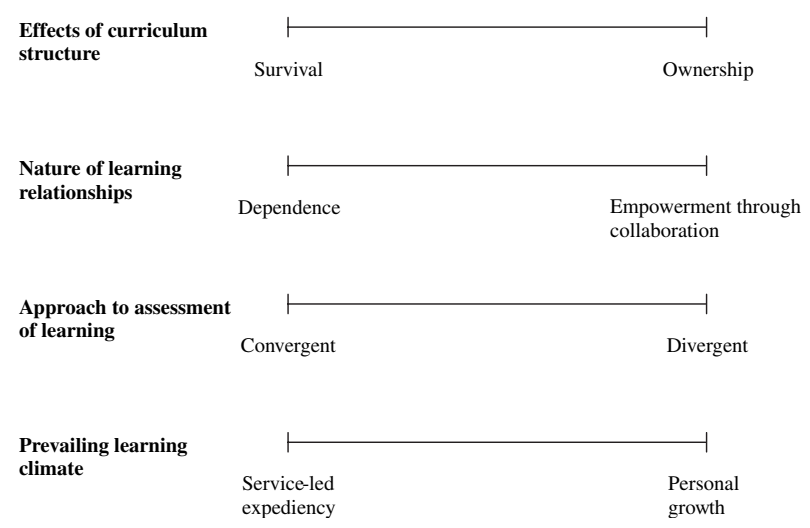

Figure 1 Emergent dimensions of the specialist learning environment. of an uncertain situation without always providing a clear sense of direction. In this view, greater structure demanded less rather than more self-direction:

'Before I think it's been amazingly self-directed. You turned up on a firm, you found your consultant and he told you what he did... and you just helped him really...you made the best or the most of it and it was very much left to chance.' (Trauma and Orthopaedics; C)

In contrast, greater structure meant trainees were taking 'ownership', identifying personal learning needs and desires and being proactive in the means of achievement. The trainer's role was to support trainees' learning decisions:

'I think having ownership, so that they can get together and say, "These are the things that we need to do," is the way ahead really. We still have some oversee, but I think they feel much more in control of what they are being taught at the moment.' (Gastroenterology; C)

For some trainees this was working:

'Our training needs are met and encouraged.' (Paediatrics; SpR)

For others it was problematic:

'Trying to provide training days to cater for all specialist registrars in all specialties doesn't work and people become demotivated.' (Gastroenterology; SpR)

\section{Nature of learning relationships}

On one hand a familial view of learning relationships reflected a wish to 'look after' trainees and concern that lack of time militated against this. This contrasted with concerns about 'spoon-feeding' and learners being encouraged to adopt a dependent role because of greater curriculum structure:

'To be a good educator you must know the person you are educating and have time to talk, to facilitate what they are doing...with other pressures I don't have time to look after my trainee as I'd like.' (Trauma and Orthopaedics; C)

'...in some ways that structure leads to a sort of "spoon-feeding" mentality and what worries me is 
that many of the trainees see that as the way forward...it worries me about the type of doctor we are training to become a consultant, if they are used to being...looked after and mothered all the time.' (Anaesthetics; C)

'Over-supervision means trainees are not very confident.' (Anaesthetics; SpR)

However, there was also a desire for more collaboration based on facilitation, reflective dialogue and empowerment. Peer support was considered important in enabling trainees to take ownership of the means of learning. For some this was more successful than for others:

'I think they bond together as quite a good group and they do encourage one another to learn...' (Paediatrics; C)

'Too many hospitals involved means registrars are spread thinly, therefore there is infrequent contact with your peer group.' (Trauma and Orthopaedics; SpR)

Flexible training sometimes placed demands on peer relationships, such that these trainees needed to negotiate for particular learning opportunities, or were considered 'flexible but inflexible' by their 'fulltime' peers:

'...I think we have to be absolutely down the middle with them, and make the most of them, rather than say, "Oh, they're not here all the time," when they're actually contributing more, and I think they need that grit to be able to say "Come on, be fair!", (Histopathology; C)

\section{Approach to assessment of learning}

The main theme here was trainees' role in learning specifically for assessment compared to learning through the assessment process. Inevitably, the power of assessment to motivate learning was acknowledged:

'...we did award some [low grades] for their lack of operating experience and word has got around now. Some of the trainees are coming to me saying,

"Oh, I want to get this case and I don't want you saying to me when we next meet that I haven't done enough operations." It's made them more enthusiastic or it's driven them to get more operating done I think.' (Trauma and Orthopaedics; C)

However, increasing emphasis on very structured or convergent methods and the reductionist style of highly specific learning outcomes were seen as problematic, leading to check-list training and a false impression of competence. Developing more divergent approaches was considered important, because trainee involvement in initiating assessment could encourage more critical reflection, as opposed to reliance on trainers' assessments to define their deficiencies. This was apparent in comments about the review of the in-service training and assessment (RITA) process, where arguments in favour of a paper-based exercise were contrasted with a desire for more dialogue and involvement on the part of trainees and trainers:

'There is too much emphasis on RITAs; it should be like the rest of the country.' (Psychiatry; SpR)

'RITA is a marriage between allowing the trainee to express him or herself, to demonstrate what they have done, and assessment...trainee self-assessment does make the trainee pause, makes them reflect.' (Adult Psychiatry; C)

The importance attached to various attributes, or the extent to which evidence, personal values and assumptions influenced decision making was reflected in participants' anxiety about the reliability of assessors' reports, and trainers' perceived reluctance to be critical of trainees' performance.

\section{Prevailing learning climate}

The learning climate for specialist registrars was portrayed as both ambivalent and complementary in terms of balance between education and service provision. The potential for bureaucratic initiatives, such as the Postgraduate Medical Education and Training Board (PMETB) ${ }^{16}$ and the European Working Time Directive (EWTD) ${ }^{17}$ to upset the balance and compromise quality was a concern, in that shortening programmes and training time was seen as possibly resulting, ultimately, in substandard doctors and consultants:

'Due to EWTD time for training is becoming shorter, hence the number of training opportunities is already reduced. Protected training would be more and more important.' (Trauma and Orthopaedics; SpR) 
'I worry that the future of training is going to be towards increasing numbers...just concentrating on the numbers not the quality...so I have a great deal of anxiety about training in the short to medium-term. In the longterm...I think people will see the light, but at a great cost unfortunately.' (Adult Psychiatry; C)

The pressure of service demands was also seen to direct trainees towards the acquisition of prescribed knowledge and skills, rather than active engagement with reflective and participative learning:

'Trusts are very keen to appoint [consultants] and therefore you don't have to have done as much to get a post. Therefore people's desire to get all the other things is reduced, because they don't see it as necessary. The challenge for us is to encourage them to [still see it as important].' (Anaesthetics; C)

'Shift working makes study leave nigh impossible when you want it and is also affecting ability to attend clinics, especially when rotas are understaffed.' (Paediatrics; SpR)

'It's easier to concentrate on training and studying...if you don't have to be exposed to the aggressiveness of the management team.' (Anaesthetics; SpR)

'More flexibility to work temporarily in other deaneries, to take advantage of a wider choice of experience would be good.' (Psychiatry; SpR)

Ideally, work-based educational environments for specialist registrars should connect effective and meaningful service delivery with academic and experiential learning, personal growth and professional responsibility. Making this a reality for specialist registrars through effective mediation between service imperatives and learning needs was a key theme in the doctors' feelings about the specialist learning climate:

'...we've had very good help from [hospital]...they are not part of our training programme, but they are willing to supervise them... When we started doing this the departments were very resentful ... "If they go away for a month what will happen to us?" Now they have got used to it...there is slowly acceptance.' (Histopathology; C)
'I think the general population wants quality. Service and training are intricately wound together; you can't separate them...to have high quality consultations you of course need trainees, but they need to be supervised and to have feedback on their work, and the Trust needs to sign up to that.' (Gastroenterology; C)

\section{DISCUSSION}

This early, exploratory study involved a small sample of consultants and specialist registrars. It has been valuable in creating a reflective framework for subsequent stages in the wider investigation of recruitment and retention in the West Midlands. Doctors in specialist training are engaged predominantly in workplace learning. However, workplaces are 'contested terrain'18 across which economic productivity and productive learning attempt to come to terms. Thus, what and how individuals learn at work is determined partly by how the learning process is perceived and partly by opportunities afforded by the workplace for learning to occur. The dimensions of higher specialist training described by the doctors in this study offer contrasting views of the learning process and workplace environment (Fig. 1). The items on the left in Fig. 1 represent learning as individualistic and narrow in an environment that affords economic productivity the high ground. In this context, learning outcomes might be expected to be largely instrumental. The items on the right represent learning as a communal process, emphasising broader learner participation and a constructive alliance between productivity and learning. ${ }^{19}$ Such an environment should foster more holistic outcomes.

Three models of workplace learning, outlined in Table 1, provide a useful framework for considering what this means for programme development and recruitment. ${ }^{20}$ In the first, novices acquire traditional skills through apprenticeship at the master/expert's feet, going where he or she leads, inheriting, ultimately the role and status of 'expert' (patrimony). The basis of this learning relationship is inequality. The source of the 'expert' identity lies in what Sinclair describes as the 'functional primacy' of becoming a specialist 'with all its implications for title, social status, income and power. ${ }^{5}$ This model is echoed in the consultants' recall of a more unstructured curriculum and their desire to 'look after' trainees, and registrars' wish for more hands-on experience. 
Table 1 Models of workplace learning (adapted from Rhodes and Scheeres 200420)

\begin{tabular}{|c|c|c|c|}
\hline & Patrimony model & Bureaucratic model & Facilitation model \\
\hline Mode of teaching & Apprenticeship & Formal training organised bureaucratically & Learning communities \\
\hline Mode of learning & From master to novice & Rule-bound and standard procedures & Learning partnership and collaboration \\
\hline $\begin{array}{l}\text { Source of values professional } \\
\text { identity }\end{array}$ & Social/professional status & Bureaucratic machine & Organisational mission and core values \\
\hline Learning outcomes & $\begin{array}{l}\text { Reproduction of traditional } \\
\text { knowledge and skills }\end{array}$ & Predetermined skills and competencies & Empowerment and collective agency \\
\hline Identity & Expert practitioner & Competent fit-for-purpose practitioner & Capable lifelong learner \\
\hline
\end{tabular}

The description '....a curriculum set by the bureaucracy in which... an apprenticeship pedagogy is replaced with a homogenised mass production model of learning ${ }^{21}$ ( $p$ 181) is a criticism levelled at a bureaucratic model of workplace learning. Consultants' anxiety about the consequences of this more reductionist approach was apparent in relation to assessment, particularly the dangers of learning 'for' rather than 'through' assessment, as was their resulting concern about lack of selfassessment and reflection, reluctance to engage with broader aspects of learning, and just concentrating on the numbers not the quality'. Nevertheless, this model is rooted in the principle of fitnessfor-purpose, where the identity of 'competent practitioner' is acquired by following established rules and procedures.

Through reference to ownership, peer support and self-direction, participants in the study acknowledged a shift in the balance of power and responsibility for learning reflected in a facilitation model of workplace learning. Here, learners and educators collaborate as partners in horizontal 'learning communities'1 rather than hierarchical learning relationships. One's source of professional identity (as a teacher in the clinical context) lies in the shared striving to empower capable lifelong learners so that they are equipped to respond to future change. However, although an apparently worthy alternative to inequality and reductionism, this model could be seen as sacrificing safeguards and fitness-for-purpose on the altar of flexibility and negotiation.

Beckett and Gough write that: 'The formation of a truly professional practitioner in medicine involves both "liberal" and "instrumental" learning, that is, learning which is at once open-minded and openended, and yet also tightly focused on wellness and the public good. ${ }^{22}$

The breadth of imperatives in specialist education means that the dimensions in Fig. 1 represent con- trasting, but not necessarily conflicting, values, or continua rather than exclusive categories. Such breadth urges constructive co-existence rather than struggle among the models of workplace learning outlined above, as well as freedom to manoeuvre along the continua described, in order to achieve both instrumental and liberal learning outcomes. Thus, focus on predetermined competencies need not, necessarily pose a threat to empowerment and ownership of the learning process. It should be possible to be apprenticed and on the periphery of practice in some respects, and at the same time engage in collective agency and full participation as part of a learning community.

In Fig. 2 the models of workplace learning interact with one another in relation to the learning outcomes they promote and the professional identities they espouse. In this conception, the patrimony model has the potential to maintain a balance between merely instrumental and exclusively liberal learning outcomes. A learning environment that not only provides necessary safeguards in terms of predefined competences, but that also affords opportunities for experiential apprenticeship, while fostering empowerment and agency within a learning community, should enable specialist registrars to construct an enriched, hybrid identity born out of all 3 workplace models. Questions for ongoing investigation include:

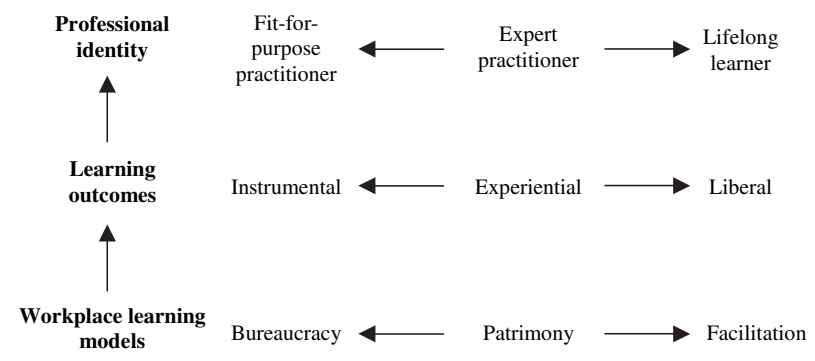

Figure 2 Interacting elements of an enriched learning environment. 
- Should selection of potential trainees take account of learning skills and dispositions that could help optimise their ability to negotiate across differing workplace learning models?

- To what extent are different learning environments, even within the same specialty, capable of fostering an enriched professional identity among higher specialist trainees, and how does this affect recruitment and career satisfaction?

The workplace learning models described suggest a useful framework for evaluation and comparison.

Inevitably, the extent to which policy intentions validate a particular model of workplace learning over another will influence how far learning environments are enabled to foster an appropriate balance of instrumental and liberal learning outcomes, as well as enrich the professional identity of doctors. The more closely the meanings and rationales implicit within policy intentions are acceptable to the stakeholders who must enact policy, the more effective the learning environment will be.

Dissonance, as voiced by the doctors in this study, makes it less likely that policy will emerge as practice, that the walk will match the talk. ${ }^{23}$ The dilemma for specialist training and recruitment, is summed up by Talbot, ${ }^{21}$ who asks whether we should be content to satisfy the demands of an apparently impoverished policy by 'reflex acquiescence', or 'have the courage to champion the long view' by advocating a more enriched environment for learning and career development. Achieving and maintaining satisfactory levels of recruitment and retention in all specialties seem to depend on our determination to do the latter.

\section{CONCLUSION}

Debate surrounding changes in specialist training is passionate and varied. One extreme depicts these changes as representing a golden opportunity to enhance efficiency and quality of service delivery; the other portrays them as a dumbing-down process that will downgrade the end-product of higher specialist training. Changes in the postgraduate education of doctors seem set to continue well into the future. How these are reflected in the balance between different models of workplace learning, and how this influences doctors' sense of professional identity suggests a useful basis for examination of career satisfaction and recruitment to specialties.
Contributors: VC designed and carried out the research, and drafted, revised and prepared the article for submission. $\mathrm{CH}$ and JP were involved in data analysis and interpretation, and revision of the article. SF was involved in the conception of the paper, data acquisition and critical revision of the paper. All the authors approved the final version.

Acknowledgements: the authors gratefully acknowledge the helpful comments on an earlier draft of this paper of Professor David Wall, West Midlands Deanery and Centre for Research in Medical and Dental Education.

Funding: this study was funded by the West Midlands Deanery, UK.

Conflicts of interest: none.

Ethical approval: $\quad$ this study was approved by the South Birmingham Local Research Ethics Committee.

\section{REFERENCES}

1 Hodkinson P, Hodkinson H. Individuals, communities of practice and policy context: school teachers' learning in their workplace. Stud Contin Educ 2003;25 (1):3-21.

2 Beckett D, Hager P. Life, Work and Learning: Practice in Postmodernity. Routledge International Studies in the Philosophy of Education 14. London/New York: Routledge 2002.

3 Wenger E. Communities of Practice: Learning, Meaning and Identity. Cambridge: Cambridge University Press 1998.

4 Munthe E. Teachers' workplace and professional certainty. Teach Teacher Educ 2003;19 (8):801-13.

5 Sinclair S. Making Doctors - an Institutional Apprenticeship. Oxford: Berg 1997.

6 Roff S, McAleer S. What is educational climate? Med Teacher 2001;23 (4):333-6.

7 Genn JM. AMEE Medical Education Guide No. 23. Part 2. Curriculum, environment, climate, quality and change in medical education - a unifying perspective. Med Teacher 2001;23 (5):445-54.

8 Roff S, McAleer S, Harden RM et al. Development and validation of the Dundee Ready Education Environment Measure (DREEM). Med Teacher 2004;19 (4):25999.

9 Roff S, McAleer S, Skinner A. Development and validation of an instrument to measure the postgraduate clinical learning and teaching educational environment for hospital-based junior doctors in the UK. Med Teacher 2005;27 (4):326-331.

10 Holt MC, Roff S. Development and validation of the Anaesthetic Theatre Educational Environment Measure (ATEEM). Med Teacher 2004;26 (6):553-8.

11 Calman KC. Hospital Doctors. Training for the Future. [The Calman Report.] London: Department of Health 1993.

12 Bullock A, Burke S, Wall D. Curriculum and assessment in higher specialist training. Med Teacher 2004;26 (2):174-7. 
19 Pillay H, Boulton-Lewis G, Wilss L. Conceptions of work and learning at work: impressions from older workers. Stud Contin Educ 2003;25 (1):95-111.

20 Rhodes C, Scheeres H. Developing people in organisations: working (on) identity. Stud Contin Educ 2004;26 (2):175-93.

21 Talbot M. Monkey see, monkey do: a critique of the competency model in graduate medical education. Med Educ 2004;36 (6):567-92.

22 Beckett D, Gough J. Perceptions of professional identity: a story from paediatrics. Stud Contin Educ 2004;26 (2):195-208.

23 Nicholl K, Chapell C. Policy effects: 'flexible learning' in higher education and the 'de-differentiation' of the vocational sector. Stud Contin Educ 1998;20 (1):39-50.

Received 1 April 2005; editorial comments to authors 24 May 2005; accepted for publication 17 November 2005 